\title{
Trauma History and Mental Health of North Korean Defectors
}

\author{
Jin-Won $\mathrm{Noh}^{1} \cdot$ So Hee Lee ${ }^{2}$ (D) \\ Accepted: 15 September 2020 / Published online: 6 October 2020 \\ (C) The Author(s) 2020
}

\begin{abstract}
Purpose of Review This study aimed to review the mental health status of North Korean defectors (NKDs) and related factors. Interventions to promote their mental health and issues to be dealt with are also reviewed.

Recent Findings NKDs are often exposed to multiple severely traumatic events, both in North Korea and surrounding their defection. Furthermore, they face sociocultural barriers in adapting to a new society. Past exposure to traumatic events, longer defection periods, forced repatriation, psychological factors, and acculturative stress such as perceived discrimination, low income, family violence, and health complaints contribute to negative effects on mental health and obstruct their adaptation to life in the Republic of Korea.

Summary It is necessary to develop evidence-based programs to promote NKDs' mental health and help them to adapt to their new society. An NKD cohort study would be helpful to reveal their long-term mental health prognoses and interactions with preand post-migration factors.
\end{abstract}

Keywords Trauma $\cdot$ Mental health $\cdot$ Post-traumatic stress disorder $\cdot$ North Koreans refugees $\cdot$ Social adaptation $\cdot$ Intervention

\section{Introduction}

North Korean defectors (NKDs) are often exposed to traumatic events, both in North Korea and surrounding their defection $[1 \bullet]$. Furthermore, they face various sociocultural barriers when adapting to their new society [2]. Early interviews with NKDs during and immediately after the famine revealed, not surprisingly, that hunger and food shortages were the major factors motivating their escape from their homeland [3]. A Human Rights Watch report from 2002 stated that hunger was one of the key motives for flight. Others included frustration over lack of opportunities, loss of status, political persecution, and the desire to live in similar environments to North Koreans who live outside their country [4].

More than 33,000 NKDs have entered the Republic of Korea since 1998 [5]. Over 70\% of these people were women

This article is part of the Topical Collection on Personality and Impulse Control Disorders

So Hee Lee

sohee.lee@nmc.or.kr

1 Department of Health Administration, Dankook University, Cheonan, Republic of Korea

2 Department of Psychiatry, National Medical Center, Eulji-ro, Jung-gu, Seoul 04564, Republic of Korea and around 55\% were in their 30s and 40s. In most cases, NKDs escape through a third country then come to South Korea. These are mainly Southeast Asian countries or China [6]. Furthermore, about $70 \%$ of NKDs reported having stayed in a third country and about $80 \%$ had stayed in the Republic of Korea for more than five years [7].

Some NKDs have been deported from China before reaching the Republic of Korea. Most NKDs go to China because it is easily geographically accessible from North Korea. However, NKDs are repatriated to North Korea if they are arrested by Chinese police. This repatriation experience is particularly traumatic, especially considering that it usually results in torture, possible execution, and incarceration [1•].

Additionally, NKDs often have multiple experiences of human rights violations in North Korea, including arbitrary arrest, torture, inhumane treatment, and forced witnessing of public executions [8]. Investigations into the mental health consequences of human rights abuses have revealed increases in symptoms of anxiety, depression, and post-traumatic stress disorder (PTSD). Indeed, these symptoms have been found to be significantly associated with exposure to cruel and inhu-

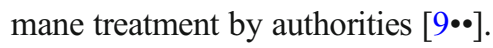

Thus, the purpose of the present study was to review recent studies about the mental health of NKDs and elucidate factors related to their mental health, including traumatic experiences and stressful events. The present review may deepen current 
insights into the mental health risk factors of NKDs and inform the administration of practical interventions for ameliorating mental health problems such as PTSD through the development of individually tailored programs. Furthermore, the present findings may contribute to the establishment of policy alternatives regarding the improvement of mental health in NKDs by emphasizing their unique traumatic experiences and preventing further stressful events.

\section{Current Mental Health Status of NKDs}

According to previous studies on immigrants and refugees, mental health can be the key determining factor for successful integration into a new culture and society $[10,11]$.

Refugees affected by multi-traumatic stressors are at high risk of trauma-related mental disorders, including anxiety, PTSD, and depression. Recent findings have revealed that $44-46 \%$ of NKDs exhibited depressive symptoms [12, 13] and $43-54 \%$ of NKDs exhibited symptoms of anxiety [14, 15]. When using self-reported scales, PTSD symptoms were observed in $40-52 \%$ of adult NKDs $[12,16]$ and $13-30 \%$ of adolescent NKDs $[17,18]$. However, studies using the Structured Clinical Interview for DSM (SCID) found that the prevalence of PTSD among NKDs was lower, at $4 \sim 5 \%$ $[19,20]$.

Studies that have compared the current mental health status between South Korean natives (SKNs) and NKDs have consistently reported significantly higher rates of mental health problems like depression, anxiety, PTSD, and insomnia in NKDs [21, 22]. The prevalence of depression (56.3\%), anxiety $(60.1 \%)$, and PTSD $(22.5 \%)$ in NKDs [9.•] is notably higher than the prevalence of depression (3.1\%), anxiety $(6.8 \%)$, and PTSD $(0.6 \%)$ in SKNs [23]. In one study, the prevalence of insomnia (38\%) in NKDs was more than four times higher than that seen in SKNs (9\%) [21]. Additionally, when comparing general psychological adaptation, adolescent NKDs reported more severe psychological problems, such as attention and thought problems, post-traumatic stress and somatic symptoms, and lower social functioning than their SKN peers [24].

The lifetime prevalence of suicidal ideation (28.3\%), suicide plans (13.3\%), and suicide attempts (17.3\%) among NKDs are reported to be higher than the rates reported in a nationwide sample of SKNs (suicidal ideation: 15.4\%, suicide plans: $3.0 \%$, and suicide attempts: $2.4 \%$ ) [25]. Moreover, the rates of suicidal thoughts and behaviors (suicidal ideation, suicidal plans, or suicide attempts) among NKDs are much higher $(31.3 \%)$ than the nationwide prevalence in the Republic of Korea, Western countries, and Asian countries, which range from 0.9 to $15.9 \%$ [26, 27].

Furthermore, severe depression, anxiety, PTSD, or somatization symptoms in NKDs have been found to be negatively correlated with their overall satisfaction with living in the Republic of Korea [28]. Thus, a strategy that focuses on relieving psychiatric symptoms in traumatized refugees may help them to adapt to their new environment.

\section{Trauma Experiences as Factors Related to Mental Health in NKDs}

The ability to identify the NKDs who are at high risk of poor mental health would help services to provide appropriate medical and social support.

\section{Trauma Experiences of NKDs in North Korea and During Defection}

Both children and adults are consistently reported to be fleeing North Korea because of political oppression and poverty. NKDs are affected by a variety of adverse life experiences, such as traumatic events. These individuals have often been exposed to political violence and life-threatening situations related to famine. Furthermore, prolonged insecurity due to chronic illegal status in a third country is particularly traumatic for NKDs.

Most studies have found that the number and severity of these traumatic experiences are predictive of a wide range of psychiatric disorders, including PTSD, in NKDs [21, 28, 29••, 30, 31]. Moreover, various traumatic experiences experienced by NKDs negatively affect their life satisfaction, especially economic satisfaction, in the Republic of Korea [28]. Indeed, the negative effect of trauma experiences is mediated by psychiatric symptoms.

Around $95 \%$ of adult NKDs have reported at least one exposure to trauma, while $90 \%$ report having experienced different types of trauma, which most frequently included witnessing public executions, personally experiencing lifethreatening starvation, witnessing the deaths of friends or family members from starvation, witnessing serious physical assaults, and escaping arrest following defection [31]. Adolescent NKDs are no exception, $88.7 \%$ of the young NKDs had experienced at least one traumatic event that met the DSM-5 A criteria [17, 32]. Additionally, 45.2\% reported having experienced between two and four traumatic events and $30.6 \%$ had experienced more than five traumatic events. Moreover, female NKDs are exposed to the additional risk of sexual violence. Almost one in four female NKDs reported sexual victimization, such as rape, sexual harassment, and sex labor. This occurred in both North Korea and third countries [33].

Specifically, NKDs report that they have been through various violent and traumatic experiences in North Korea [ $1 \bullet$, 20]. These include witnessing death from starvation (56.6 87.4\%), experiencing great pain from illness or being 
gravely ill due to lack of treatment (16.1-62.2\%), witnessing a public execution (43.5-87.4\%), imprisonment (17.3-27.4\%), physical violence (17.7-28.1\%), and torture (6.5-20.9\%). During escape, NKDs have reported being exposed to traumatic events such as human trafficking (25\%), hiding for fear of being found by others (25.8-83.4\%), being inspected by secret agents or North Korean guards at the border (17.7$52.3 \%$ ), having life-threatening shortages of food and water (17.4-38.6\%), and being robbed of food, money, and water in their possession (4.8-23.2\%).

Regarding human rights violations in North Korea, $29.3 \%$ of NKDs suffered inhumane treatment and torture, $74.6 \%$ had no freedom of movement and residence, $49.1 \%$ experienced discrimination, and $63.8 \%$ experienced denials of freedom of expression, thought, and religion [9••]. Furthermore, NKDs reported organized violations of the right to food, health, and livelihood, and forced labor was also common $(70.3 \%)$ [9••].

Exposure to organized violence prior to entry into South Korea was reported by more than half of young NKDs (59.7\%), whereas no one reported being exposed to this type of violence in the SKN youth sample [17]. The three most common types of systematic violence were starvation $(43.5 \%)$, witnessing public execution or torture $(27.4 \%)$, and imprisonment $(21 \%)$.

\section{PTSD as a Factor Influencing Other Comorbid Mental Health Problems}

PTSD has been reported to be an influencing factor for other comorbid mental health problems. One study, a meta-analysis investigating depression, anxiety, and PTSD among NKDs, revealed strong, significant associations between depression, anxiety, and PTSD [34]. The relationships between depression, anxiety, and PTSD were stronger in adults and in those who had spent more than five years in third countries.

PTSD could mediate mental health problems, especially interpersonal trauma $[35,36]$. However, they observed that trauma exposure, both interpersonal exposure and noninterpersonal exposure, had no direct association with comorbid mental health problems.

PTSD symptoms in young NKDs were strongly related to insomnia and depression [18]. Furthermore, PTSD was found to affect insomnia via depression, which indicates that more severe PTSD is associated with a greater likelihood of developing sleep problems via depression.

NKDs have been reported to exhibit attention deficits that could be related to their psychiatric symptoms, particularly dissociation. One study on the performance of NKDs on attention subjects showed that attention deficits were associated with dissociative experiences. Dissociation in NKDs may be a result of their traumatic experiences.

\section{Defection-Related Variables in NKRs}

Additionally, several defection-related variables were revealed to be risk factors for mental health problems among NKDs.

NKDs who stayed longer in third countries reported higher levels of psychological problems, such as PTSD, depression, anxiety, and suicidal ideation [22, 37]. Given that longer periods in third countries have been found to be associated with more traumatic experiences among NKDs [20], a longer stay might increase the mental health risks posed by traumatic experiences or distressing events during the immigration process.

One study found that, in NKDs with premigration trauma, those with repatriation experiences were at greater risk of experiencing overall psychopathological symptoms [38]. Around $26 \%$ of NKDs had experienced at least one repatriation [39]; these individuals had more than twice the number of escape attempts [22]. These experiences were associated with high rates of suicidal ideation or depression/anxiety among NKDs.

\section{Psychological Factors Influencing the Relationship Between Traumatic Experiences and Mental Health Problems}

Some psychological factors were reported to be risk factors in relationships between the traumatic experiences and mental health problems of NKDs, namely alexithymia, expressive suppression as an emotional regulation strategy, and negative cognitions of personal failure.

The moderating effect of alexithymia in the association between PTSD and the number of traumas experienced in NKDs was emphasized; more severe PTSD was reported in refugees with a higher degree of alexithymia and who had experienced more traumatic experiences [31]. They suggested that clearly identifying and expressing emotions becomes more crucial for decreasing PTSD symptoms as individuals experience more traumatic events.

Regarding emotion regulation strategies, the use of expressive suppression among young NKDs significantly worsens the effects of early trauma on both depressive and attentiondeficit hyperactivity disorder (ADHD) symptoms, which indicates that it could be a risk factor for mental health issues [40]. However, cognitive reappraisal seems to slow the effect of expressive suppression on depressive symptoms.

One study examined the relationship between early traumatic experiences, negative automatic thoughts, and depression in young NKDs ( $N=109,13-29$ years) living in the Republic of Korea. Early traumatic experiences were positively associated with depressive symptoms both directly and through thoughts of personal failure [41]. Interventions that 
target negative cognitions of personal failure could decrease the risk of depression in NKDs.

Lower resilience was found to be related to more severe depression and prolonged severe depression in a one-year follow-up study that investigated changes in depression in young NKDs [42]. Additionally, in models predicting clinical depression (dichotomous), resilience fully mediated the relationship between family cohesion and clinical depression in NKDs [13].

\section{Psychosocial Stress During Adaption to New Society and Its Relationship With Mental Health in NKDs}

A 7-year follow-up study on the mental health of NKDs in South Korea reported that the rate of PTSD and PTSD symptom scale scores decreased significantly from baseline over the study period [43]. However, staying more than 5 years after entering South Korea was related to high rates of suicidal ideation among NKDs $[22,44]$. Additionally, female adult NKDs who had been resettled in South Korea for longer periods experienced more severe depressive symptoms than those in the earlier stages of resettlement [21]. These findings suggest that NKDs were suffering from post-migratory life stress despite the common traditional cultural heritage, common language, and systemic support offered by nongovernmental organizations and the South Korean government. Several acculturative stresses related to the mental health of NKDs have been reported, including perceived discrimination, financial difficulties, poor family relationships, and physical illnesses.

\section{Perceived Discrimination}

One study found that the perception of discrimination and poor social and cultural adaptation were associated with increasing levels of depressive symptoms in a sample of NKDs taken from the 2010 National Survey. Perceived discrimination was reported to play a moderating role [45]. Perception of discrimination attenuated the relation between fewer depressive symptoms and better adaptation, when they experienced no perception of discrimination. This means that we have underestimated the importance of educating South Koreans to be accepting hosts who value diversity despite living in a homogeneous society.

\section{Low Income}

Financial difficulties may put NKDs at greater risk of mental health problems. Many reports have found that adult NKDs with lower monthly incomes are more vulnerable to a wide range of psychiatric symptoms, including anxiety, depression, and somatization [13, 46, 47]. It should be noted that no independent association was observed between low-income status and depressive symptoms when controlling for other confounding variables, such as family characteristics, sociocultural adaptation, and physical health [45]. This suggests that NKDs' financial status may influence their psychiatric symptoms.

\section{Family Relationships}

NKDs in South Korea are reported to be at a higher risk $(57.1 \%)$ of intimate partner violence (IPV) than SKNs (9.9\%) [48]. A tolerant attitude and stress were significantly related to IPV against women in NKDs. However, child abuse and children witnessing IPV between parents were the main factors contributing to IPV against women in SKNs.

A study that examined the association between the amount of organized family violence and psychopathology reported that experiences of family violence were significantly more frequent among young NKDs than in young SKNs (56.5\% vs. $33.8 \%$ ). Regarding the prevalence of various forms of family violence in their lifetime, compared with young SKNs, young NKDs had significantly higher rates of neglect (25.8\% vs. $6.2 \%$ ) and physical abuse (32.3\% vs. $10.8 \%$ ), whereas psychological abuse did not vary between these two groups. The authors observed that the severity of depressive symptoms and PTSD in young NKDs was associated with the number of family violence and traumatic events, but not with higher levels of organized violence [17]. These findings suggest that abusive experiences by family members are strongly linked to the psychopathology of NKD adolescents in the context of organized violence.

The level of emotional suppression and familial cohesion are reported to be significantly associated with suicidal ideation and suicide attempts among young NKDs, after controlling for other socioeconomic variables [49]. Familial cohesion, but not family adaptability, is significantly associated with depression among NKDs [13]. Familial and individual interventions, particularly those focused on encouraging familial cohesion, could be useful for young NKDs as they are at high risk of suicide ideation and depression.

A study that conducted quantitative and qualitative interviews with NKDs found that there is a significant link between previous victimization by political violence in North Korea and abuse of offspring in the Republic of Korea, the resettled country [50]. The mediator or mechanism underlying this association has not yet been identified. The authors hypothesized that this link was mediated by PTSD or alcohol problems, but this prediction was not supported. Further studies are needed to clarify how family violence in NKDs should be dealt with, while also considering the intergenerational transmission of trauma. 


\section{Physical Health}

Physical health and health behavior appear to be closely associated with mental health problems in NKDs. The number of physical illnesses and presence of at least one chronic health complaint have been found to be predictive of overall psychological problems in adult NKDs [19, 51]. Regarding the relationship between physical health and PTSD, one study that examined medical records over approximately 10 years found that NKDs with PTSD use outpatient services more frequently than others $[52 \bullet \cdot]$. They require higher total revenue than NKDs without PTSD. Additionally, patients with PTSD frequently used a variety of medical services. A greater number of traumatic experiences during their escape was also associated with the frequency of physician visits among NKDs [53].

With regard to health behavior, NKD adolescents reported higher current smoking, drinking, and drug-use rates than SKN adolescents [54]. Furthermore, perceived stress, smoking, and drinking experiences of NKD adolescents were related to depression. A specialized approach for NKD adolescents is required to promote proper health behaviors and adaptation to South Korean society.

\section{Interventions to Improve Mental Health in NKDs}

Despite the large number of traumatized refugees, no effective treatment for trauma in refugees and immigrants has yet been developed.

One follow-up study investigated traumatized refugee patients receiving treatment at the Competence Center for Transcultural Psychiatry in Copenhagen, which consisted of a combination of trauma-focused cognitive behavioral therapy (TFCBT), sertraline, mianserin treatment, and psychoeducation [55]. Patients had several co-morbidities such as depression, pain, untreated somatic complaints, and PTSD. They found less improvement in PTSD when patients received public subsidies, less improvement in depression when patients reported pain in the upper extremities, and a positive relationship between the systematic use of cognitive behavioral therapy (CBT) methods and improvements in patient condition.

Another randomized controlled clinical trial conducted at the same center used a $2 \times 2$ factorial design (antidepressants, TFCBT, antidepressants and TFCBT, waiting list) [55]. The authors found a small but significant effect of treatment with medicine on blinded observer-ratings of depression and anxiety. Indeed, they also found a large effect on non-blinded ratings of functioning and a small effect of intervention type on self-reported levels of functioning and headaches. No effect of psycho-therapy on any outcome was identified, and there was no effect of psycho-therapy or medicine on PTSD.
Narrative exposure therapy (NET) has been suggested as a treatment option for traumatized young NKDs, and may also be effective for the treatment of sleep problems caused by traumatic experiences [56]. The study found clinically significant reductions in PTSD, depression, and internalizing and externalizing symptoms in the NET group, but not in the treatment-as-usual group. NET also resulted in a significant improvement in insomnia symptoms and sleep quality.

We should consider the possibility that stigma around mental illness among NKDs acts as a barrier to the provision of proper interventions. NKDs have been found to have lower perceived stigmas in relation to depression and higher perceived stigmas in relation to psychosis and alcoholism than SKNs [57]. However, the perceived stigma associated with attempted suicide was very similar in the two groups. Interestingly, NKDs who had spent more than one year in a transit country exhibited an association between lower alcoholism and perceived stigma of psychosis. NKDs who had experienced compulsory repatriation to North Korea or a North Korean family in South Korea exhibited an association between higher perceived stigma and depression. Another study found that knowledge of mental illness in NKDs was associated with their attitude toward people with mental illness, which indicates that we can improve attitudes by educating NKDs on mental illness [58].

NKDs' health literacy and drug knowledge levels have been found to be low, and many drug misuse cases have been identified in women in their 40s [59]. A significant association between health literacy and drug knowledge has also been reported. Four issues have been suggested to affect NKDs: (1) their tendency to see their psychological symptoms as being physical in nature, (2) their tendency to trust in the belief systems established in North Korea and in their ability to selfdiagnose, (3) their tendency to see the available medical treatment as inappropriate, and (4) their feeling that the treatment they received was ineffective and slow because of capitalism.

\section{Conclusions}

The traumatic experiences and psychosocial stress affecting NKDs are mental health risk factors that hinder their successful resettlement in the Republic of Korea. Previous studies have consistently found that NKDs have experienced traumatic events; longer stays in third countries; forced repatriation; psychosocial stresses during adaptation to their new society such as perceived discrimination, low income, and poor family relationships; and physical health conditions (Table 1).

These findings suggest the need for enhanced awareness about human rights issues in North Korea. We also need to provide more resources to prevent victimization among 
Table 1 Factors related to mental health of North Korean defectors

\begin{tabular}{|c|c|c|c|}
\hline Premigration & Migration & Post-migration & Psychology \\
\hline $\begin{array}{l}\text { - Traumatic experiences }[1 \cdot, 9 \cdot \bullet, 17,20] \\
\text { - Witnessing death from starvation } \\
\text { - Witnessing public execution } \\
\text { - Experiencing great pain from illness or being } \\
\text { gravely ill due to lack of treatment } \\
\text { - Imprisonment } \\
\text { - Physical violence } \\
\text { - Torture etc. }\end{array}$ & $\begin{array}{l}\text { - Traumatic experiences }[1 \cdot, 20] \\
\text { - Hiding for fear of being found by } \\
\text { others } \\
\text { - Human trafficking } \\
\text { - Inspected by North Korean guards or } \\
\text { secret agents at the border } \\
\text { - Shortage of food and water to a } \\
\text { life-threatening level } \\
\text { - Robbed of money, food, and water } \\
\text { in their possession etc. } \\
\text { - Long stays in third countries } \\
\text { [20, 22, 37] } \\
\text { - Repatriation experiences }[38]\end{array}$ & $\begin{array}{l}\text { - Long staying periods after entrance } \\
\quad[21,22,44] \\
\text { - Perceived discrimination }[10] \\
\text { - Low income }[13,46,47] \\
\text { - Family relationships (family violence, } \\
\quad \text { family cohesion) }[17,48,49] \\
\text { - Physical illnesses }[19,51]\end{array}$ & $\begin{array}{l}\text { - Alexithymia [31] } \\
\text { - Emotion } \\
\text { regulation } \\
\text { strategy [40] } \\
\text { - Thoughts of } \\
\text { personal failure } \\
\text { [41] } \\
\text { - Resilience [42] }\end{array}$ \\
\hline
\end{tabular}

NKDs. Additionally, more rigorous studies are required to determine the long-term trajectory of psychological problems of NKDs and evaluate the long-term interactions among mental health problems, including PTSD in NKDs and their preand post-migration experiences, as well as their personal characteristics. To achieve these goals, an NKD cohort study that follows the mental health and social integration of subjects registered upon entrance to the Republic of Korea would be helpful.

There are insufficient studies on the development of evidence-based therapies for NKDs. Future studies should be developed to implement targeted psychiatric interventions through adequate policies. Previous findings suggest that the effectiveness of therapies for PTSD in traumatized refugees is questionable, and NKDs suffer from numerous psychiatric problems and co-morbidities. Given that the negative effects of trauma were primarily mediated by psychiatric symptoms, strategies that aim to relieve the psychiatric symptoms of traumatized refugees may facilitate their successful adaptation to life in the Republic of Korea.

Considering the considerable stigma surrounding mental illness and the low health literacy of NKDs residing in South Korea, it is necessary to provide community-based information to vulnerable groups to promote knowledge of mental illness and ensure the safe use of medications.

Funding This study was supported by a grant from the Korean Mental Health Technology R\&D Project, Ministry of Health \& Welfare, Republic of Korea (HL19C0007).

\section{Compliance with Ethical Standards}

Conflict of Interest The authors declare that they have no competing interests.

Human and Animal Rights and Informed Consent This article does not contain any studies with human or animal subjects performed by any of the authors.
Open Access This article is licensed under a Creative Commons Attribution 4.0 International License, which permits use, sharing, adaptation, distribution and reproduction in any medium or format, as long as you give appropriate credit to the original author(s) and the source, provide a link to the Creative Commons licence, and indicate if changes were made. The images or other third party material in this article are included in the article's Creative Commons licence, unless indicated otherwise in a credit line to the material. If material is not included in the article's Creative Commons licence and your intended use is not permitted by statutory regulation or exceeds the permitted use, you will need to obtain permission directly from the copyright holder. To view a copy of this licence, visit http://creativecommons.org/licenses/by/4.0/.

\section{References}

Papers of particular interest, published recently, have been highlighted as:

- Of importance

- Of major importance

1. Jeon WT, Yu SE, Cho YA, Eom JS. Traumatic experiences and mental health of North Korean refugees in South Korea. Psychiatry Investig. 2008;5(4):213-20. https://doi.org/10.4306/pi.2008.5.4. 213 This study provides a thorough description of unique traumatic experiences of North Korean defectors.

2. Jeon W, Min S, Lee M, Lee E. A study on adaptation of North Koreans in South Korea. J Korean Neuropsychiatr Assoc. 1997;36:145-61.

3. Friends G. Tumangang-ŭl Kŭnnŭon Saramdŭl (People who have crossed the Tumen River). Seoul; 1999.

4. Human Rights Watch. The invisible Exodus: North Koreans in the People's Republic of China. New York, 2002.

5. Ministry of Unification. Number of North Korean refugees entered the South, 2020. https://www.unikorea.go.kr/content.do? $\mathrm{cmsid}=$ 3099. Accessed June 30, 2020.

6. Haggard S, Noland M. The North Korean refugee crisis: human rights and international response. Washington, DC: US Committee for Human Rights in North Korea; 2006.

7. Korea Hana Foundation. Survey on social integration of North Korean defectors. Seoul: Korea Hana Foundation; 2019. p. 2020. 
8. Kilovaty I. Report of the Commission of Inquiry on Human Rights in the Democratic People's Republic of Korea: green light for humanitarian intervention, vol. 6: Creighton Int'1 \& Comp LJ; 2015. p. 1.

9.• Cha J, Surkan PJ, Kim J, Yoon IA, Robinson C, Cardozo BL, et al. Human rights as political determinants of health: a retrospective study of North Korean refugees. Am J Prev Med. 2018;55(2): 271-9. https://doi.org/10.1016/j.amepre.2018.04.006 This study highlights mental health consequences of human rights violations in North Korea and suggests the need for a collaborative preventive response from global health beyond the conventional approach.

10. Jeon WT. Review of adaptation and mental health of refugees and perspectives and counterplots in Korean reunification process. J Korean Neuropsychiatr Assoc. 1997;36:3-18.

11. Tyhurst L. Coping with refugees. A Canadian experience: 19481981. Int J Soc Psychiatry. 1982;28(2):105-9. https://doi.org/10. 1177/002076408202800204.

12. Lee YJ, Jun JY, Lee YJ, Park J, Kim S, Lee SH, et al. Insomnia in North Korean refugees: association with depression and posttraumatic stress symptoms. Psychiatry Investig. 2016;13(1):6773. https://doi.org/10.4306/pi.2016.13.1.67.

13. Nam B, Kim JY, DeVylder JE, Song A. Family functioning, resilience, and depression among North Korean refugees. Psychiatry Res. 2016;245:451-7. https://doi.org/10.1016/j.psychres.2016.08. 063.

14. Ahn S, Jon D, Hong H, Jung M, Kim H, Hong N. Mental health of North Korean refugees: depression, anxiety and mental health service need. J Korean Assoc SocPsychiatry. 2012;17(2):83-13.

15. Choi SK, Min SJ, Cho MS, Joung H, Park SM. Anxiety and depression among North Korean young defectors in South Korea and their association with health-related quality of life. Yonsei Med J. 2011;52(3):502-9. https://doi.org/10.3349/ymj.2011.52.3.502.

16. Chang M, Son E. Complex PTSD symptoms and psychological problems of the North Korean defectors. Korean J Health Psychol. 2014;19(4):973-99.

17. Park J, Catani C, Hermenau K, Elbert T. Exposure to family and organized violence and associated mental health in North Korean refugee youth compared to South Korean youth. Confl Health. 2019;13:46. https://doi.org/10.1186/s13031-019-0230-0.

18. Park J, Elbert T, Kim SJ, Park J. The contribution of posttraumatic stress disorder and depression to insomnia in North Korean refugee youth. Front Psychiatry. 2019;10:211. https://doi.org/10.3389/ fpsyt.2019.00211.

19. Cho Y, Kim Y. Predictors of mental health risks in newly resettled North Korean refugee women. Korean J Woman Psychol. 2010;15(3):509-27.

20. Kim Y, Jeon W, Cho Y. A study on the prevalence and the influencing factors of the mental health problems among recent migrant North Koreans: a focus on 2007 entrants. Unif Policy Res. 2010;19(2):141-74.

21. Lee M, Chang H, Jun J. Perceived discrimination, acculturation, acculturative stress, and depression among North Korean refugees: a mediated moderation model. Korean J Woman Psychol. 2016;21(3):459-81.

22. Shin HY, Lee H, Park SM. Mental health and its associated factors among North Korean defectors living in South Korea. Asia Pac J Public Health. 2016 Oct;28(7):592-600. https://doi.org/10.1177/ 1010539516660192

23. Cho MJ, Seong SJ, Park JE, Chung IW, Lee YM, Bae A, et al. Prevalence and correlates of DSM-IV mental disorders in South Korean adults: the Korean Epidemiologic Catchment Area Study 2011. Psychiatry Investig. 2015;12(2):164-70. https://doi.org/10. 4306/pi.2015.12.2.164.

24. Kim H, Shin H. A comparison of the mental health problems of North Korean adolescent defectors and South Korean adolescents: focused on gender and age. Korean J Woman Psychol. 2015;20(3): 347-67.

25. An JH, Lee KE, Lee HC, Kim HS, Jun JY, Chang HI, et al. Prevalence and correlates of suicidal thoughts and behaviors among North Korean defectors. Psychiatry Investig. 2018;15(5):445-51. https://doi.org/10.30773/pi.2017.11.08.3.

26. Nock MK, Borges G, Bromet EJ, Alonso J, Angermeyer M, Beautrais A, et al. Cross-national prevalence and risk factors for suicidal ideation, plans and attempts. Br J Psychiatry. 2008;192(2): 98-105. https://doi.org/10.1192/bjp.bp.107.040113.

27. Värnik P. Suicide in the world. Int J Environ Res Public Health. 2012;9(3):760-71. https://doi.org/10.3390/ijerph9030760.

28. Choi Y, Lim SY, Jun JY, Lee SH, Yoo SY, Kim S, et al. The effect of traumatic experiences and psychiatric symptoms on the life satisfaction of North Korean refugees. Psychopathology. 2017;50(3): 203-10. https://doi.org/10.1159/000468544.

29.• Lee Y, Lee M, Park S. Mental health status of North Korean refugees in South Korea and risk and protective factors: a 10-year review of the literature. Eur J Psychotraumatol. 2017;8(sup2): 1369833. https://doi.org/10.1080/20008198.2017.1369833 This study provides a systematic review on the associated factors of mental health among North Korean defectors.

30. Lim SH, Han SS. A predictive model on North Korean refugees' adaptation to South Korean society: resilience in response to psychological trauma. Asian Nurs Res (Korean Soc Nurs Sci). 2016;10(2):164-72. https://doi.org/10.1016/j.anr.2016.04.003.

31. Park J, Jun JY, Lee YJ, Kim S, Lee SH, Yoo SY, et al. The association between alexithymia and posttraumatic stress symptoms following multiple exposures to traumatic events in North Korean refugees. J Psychosom Res. 2015;78(1):77-81. https://doi.org/10. 1016/j.jpsychores.2014.09.007.

32. Elhai JD, Layne CM, Steinberg AM, Brymer MJ, Briggs EC, Ostrowski SA, et al. Psychometric properties of the UCLA PTSD reaction index. Part II: investigating factor structure findings in a national clinic-referred youth sample. J Trauma Stress. 2013;26(1): 10-8. https://doi.org/10.1002/jts.21755.

33. Kim J, Kim H, Choi K, Nam B. Mental health conditions among North Korean female refugee victims of sexual violence. Int Migr. 2017;55(2):68-79.

34. Taylor BE, Chekaluk E, Bennett J. Post-traumatic stress disorder, depression and anxiety among North Korean refugees: a meta-analysis. Psychiatry Investig. 2017;14(5):550-61. https://doi.org/10. 4306/pi.2017.14.5.550.

35. Kim YJ. Posttraumatic stress disorder as a mediator between trauma exposure and comorbid mental health conditions in North Korean refugee youth resettled in South Korea. J Interpers Violence. 2016;31(3):425-43. https://doi.org/10.1177/0886260514555864.

36. Lee YJ, Jun JY, Park J, Kim S, Gwak AR, Lee SH, et al. Effects of psychiatric symptoms on attention in North Korean refugees. Psychiatry Investig. 2016;13(5):480-7. https://doi.org/10.4306/pi. 2016.13.5.480.

37. Jung Y, Choi B. Effects of the length of stay in transit country and forcible repatriation experience on the mental health of North Korean refugee women resettled in South Korea: BPSI-NKR analysis. Korean J Woman Psychol. 2017;22(1):47-67.

38. Kim SH, Kim HK, Lee N. Psychological features of North Korean female refugees on the MMPI-2: latent profile analysis. Psychol Assess. 2013 Dec;25(4):1091-102. https://doi.org/10.1037/ a0033097.

39. Han NY, Lee SH, Yoo SY, Kim SJ, Jun JY, Won SD, et al. Predictors of PTSD among North Korean defectors visited psychiatric department of North Korean defectors treatment center. J Korean Neuropsychiatr Assoc. 2015;54(1):105-11.

40. Lee M, Lee ES, Jun JY, Park S. The effect of early trauma on North Korean refugee youths' mental health: moderating effect of 
emotional regulation strategies. Psychiatry Res. 2020;287:112707. https://doi.org/10.1016/j.psychres.2019.112707.

41. Park S, Lee Y, Jun JY. Trauma and depression among North Korean refugees: the mediating effect of negative cognition. Int $\mathbf{J}$ Environ Res Public Health. 2018;15(4):591. https://doi.org/10. 3390/ijerph15040591.

42. Park S, Kim SY, Lee ES, Jun JY. Factors related to change in depression among North Korean refugee youths in South Korea. Int J Environ Res Public Health. 2019;16(23):4624. https://doi.org/ 10.3390/ijerph16234624.

43. Jeon WT, Eom JS, Min SK. A 7-year follow-up study on the mental health of North Korean defectors in South Korea. J Trauma Stress. 2013;26(1):158-64. https://doi.org/10.1002/jts.21783.

44. Noh JW, Park H, Kwon YD, Kim IH, Lee YH, Kim YJ, et al. Gender differences in suicidal ideation and related factors among North Korean Refugees in South Korea. Psychiatry Investig. 2017;14(6):762-9. https://doi.org/10.4306/pi.2017.14.6.762.

45. Um MY, Chi I, Kim HJ, Palinkas LA, Kim JY. Correlates of depressive symptoms among North Korean refugees adapting to South Korean society: the moderating role of perceived discrimination. Soc Sci Med. 2015;131:107-13. https://doi.org/10.1016/j. socscimed.2015.02.039.

46. Shin G, Lee SJ. Mental health and PTSD in female North Korean refugees. Health Care Women Int. 2015;36(4):409-23. https://doi. org/10.1080/07399332.2013.817412.

47. Song BA, Yoo SY, Kang HY, Byeon SH, Shin SH, Hwang EJ, et al. Post-traumatic stress disorder, depression, and heart-rate variability among North Korean defectors. Psychiatry Investig. 2011;8(4):297-304. https://doi.org/10.4306/pi.2011.8.4.297.

48. Nam B, Kim JY, Ryu W. Intimate partner violence against women among North Korean refugees: a comparison with South Koreans. J Interpers Violence. 2017;1:886260517699949. https://doi.org/10. $1177 / 0886260517699949$.

49. Park S, Rim SJ, Jun JY. Related factors of suicidal ideation among North Korean refugee youth in South Korea. Int J Environ Res Public Health. 2018;15(8):1694. https://doi.org/10.3390/ ijerph15081694.

50. Emery CR, Yoo J, Lieblich A, Hansen R. After the escape: physical abuse of offspring, posttraumatic stress disorder, and the legacy of political violence in the DPRK. Violence Against Women. 2018;24(9):999-1022. https://doi.org/10.1177/ 1077801217731540 .
51. Kim S, Kim H, Kim J, Cho S, Lee Y. Relationship between physical illness and depression in North Korean defectors. Korean J Psychosom Med. 2011;19(1):20-7.

$52 . \bullet$ Noh JW, Lee Y, Park H, Lee SH. Medical expenses of North Korean defectors with post-traumatic stress disorder. Psychiatry Investig. 2019;16(2):154-8. https://doi.org/10.30773/pi.2018.12. 12 This study found that North Korean defectors with PTSD diagnose used a greater number of medical services and have higher medical expenditure than those who were not diagnosed.

53. Wang BR, Kwon YD, Jeon W, Noh JW. Factors associated with the frequency of physician visits among North Korean defectors residing in South Korea: a cross-sectional study. BMC Health Serv Res. 2015;15:90. https://doi.org/10.1186/s12913-015-0736-0.

54. Kim MJ, Yu SY, Kim S, Won CW, Choi H, Kim BS. Health behavior and factors associated with depression in North Korean adolescent defectors in South Korea: the Korea Youth Risk Behavior Web-Based Survey, 2011-2014. Korean J Fam Med. 2017;38(5):256-62.

55. Buhmann CB. Traumatized refugees: morbidity, treatment and predictors of outcome. Dan Med J. 2014;61(8):B4871.

56. Park JK, Park J, Elbert T, Kim SJ. Effects of narrative exposure therapy on posttraumatic stress disorder, depression, and insomnia in traumatized North Korean refugee youth. J Trauma Stress. 2020;33(3):353-9. https://doi.org/10.1002/jts.22492.

57. Ahn JH, Kim WH, Choi HJ, Jeon JY, Song IG, Bae JN. Stigma of mental illnesses as perceived by North Korean defectors living in South Korea. Psychiatry Investig. 2015;12(1):9-15. https://doi.org/ 10.4306/pi.2015.12.1.9

58. Noh JW, Woo JM, Park H, Jung SJ, Lee Y, Kwon YD. Factors related to the attitude of North Korean refugees towards people with mental illness. Iran J Public Health. 2018;47(Suppl 1):39-46.

59. Jeon JH, Lee IS. Health literacy, drug knowledge, and drug misuse behaviors among North Korean refugees. J Forensic Nurs. 2020;16(1):E3-E11. https://doi.org/10.1097/JFN. 0000000000000280 .

Publisher's Note Springer Nature remains neutral with regard to jurisdictional claims in published maps and institutional affiliations. 